\title{
Coercion and undue influence in decisions to participate in psychiatric research - conceptual issues Paul Appelbaum
}

\author{
Address: Dept. of Psychiatry, Columbia University, 1051 Riverside Drive, Unit 122, New York, New York 10032, USA \\ from WPA Thematic Conference. Coercive Treatment in Psychiatry: A Comprehensive Review \\ Dresden, Germany. 6-8 June 2007 \\ Published: 19 December 2007 \\ BMC Psychiatry 2007, 7(Suppl I):SI39 doi:I0.II86/I47I-244X-7-SI-SI39
}

This abstract is available from: http://www.biomedcentral.com/I47I-244X/7/SI/SI39

(C) 2007 Appelbaum; licensee BioMed Central Ltd.

The essential elements of informed consent to research include the provision of relevant information to a person who is competent to make a decision, and who is situated so as to be able to do so voluntarily. The nature of the requirement of voluntariness has been resistant to exploration. Concerns about voluntariness are usually invoked under the rubrics of coercion or undue influence. Coercion can be conceptualized as the use of morally unjustified threats to bring a person to consent to research participation. Undue influence in the research context typically involves the use of affirmative inducements to persuade a person to ignore what would otherwise be their preferences regarding research participation. Talcott Parsons [1] noted four means by which influence may be exercised, involving respectively the use of appeals to shared goals, inducement, persuasion, and power. In the context of human subjects research, evocation of shared goals may be manifest by appeals to altruism; inducement by offers to provide incentives; persuasion by the application of interpersonal pressure or by an exhortation to selfinterest; and power by the issuance of threats. Appeals to altruism, if honestly framed, are unlikely ever to constitute illegitimate constraints on choice, but the other categories can be more problematic. A final component of this conceptualization of voluntariness is the recognition that constraints on decision-making can be actual or perceived. Actual offers, pressure, or threats reflect the behavior of other people who are trying to affect the subject's decision. However, there is often a dichotomy between the behaviors of others and a subject's perception of those behaviors. Hence, both actual and perceived constraint are relevant. Perceptions are the mediating variable between behaviors of others and their impact on subjects' decisions; this approach has proven fruitful in studies of voluntariness in other contexts.
References

I. Parsons T: Sociological Theory and Modern Society New York: Free Press; 1967. 